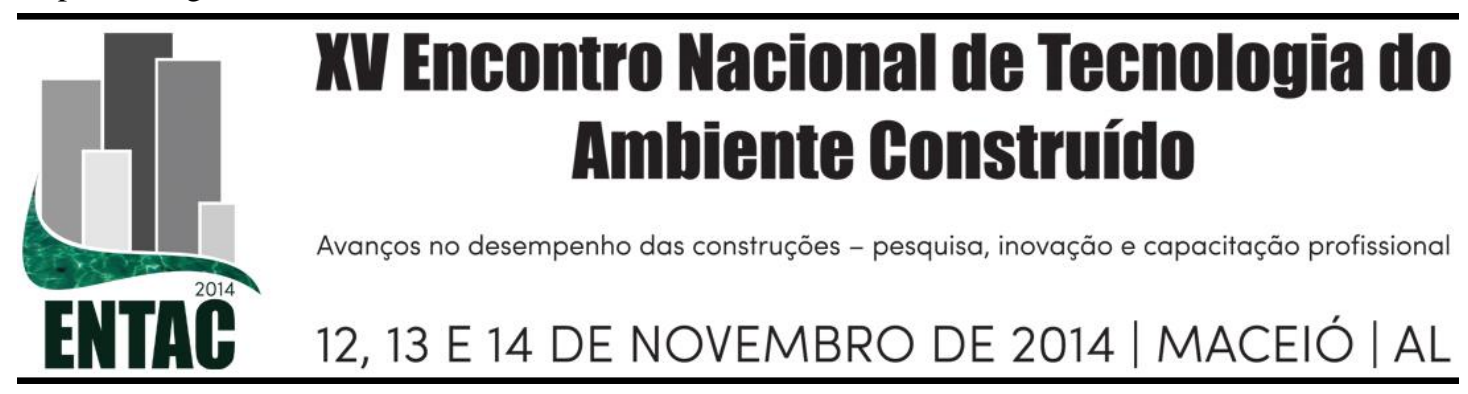

\title{
PRODUTIVIDADE DA MÃO DE OBRA NA EXECUÇÃO DE ESTRUTURA EM PAREDES DE CONCRETO
}

\author{
Melo, Roseneia (1); Torres, Túlio (2); Costa, Dayana (3); Fernandes, Luara (4) \\ (1) Universidade Federal da Bahia, e-mail: roose engcivil@hotmail.com; (2) Universidade Federal da \\ Bahia, e-mail: tuliotorrestt@hotmail.com; (3) Universidade Federal da Bahia, Telefone: (71)3283-9731, \\ e-mail: dayanabcosta@gmail.com (4) Universidade Federal da Bahia, e-mail: \\ luara.fernandes@gmail.com
}

\begin{abstract}
RESUMO
A construção civil brasileira tem se desenvolvido muito nos últimos anos, porém a ineficiência de alguns processos e os métodos construtivos artesanais de determinadas operações têm provocado uma produtividade ainda não satisfatória nos processos. Apesar dos avanços do setor em termos de materiais e técnicas construtivas, grande parte do subsetor de edificações ainda utiliza mão de obra de baixa qualificação profissional, bem como pouca mecanização, utilização de processos convencionais e técnicas simples. Diante disto, surge a necessidade de mensuração de indicadores de produtividade relacionados ao processo de paredes de concreto, por ser um sistema mais recente no mercado brasileiro e que apresenta ausência de dados de produtividade. Este trabalho tem como objetivo principal implementar um sistema de indicadores para o processo construtivo de estrutura em parede de concreto, por meio da mobilização do setor e comparação de seus desempenhos. O método de pesquisa deste trabalho envolveu: (a) sensibilização e capacitação das empresas participantes, (b) seleção das obras e concepção dos indicadores, (c) coleta dos dados e visitas de acompanhamento, (d) análise dos dados e reuniões para troca de resultados e experiências e, por fim, (e) análise comparativa entre as obras e seus processos utilizados. Esta pesquisa contribui para a criação de um banco de dados com informações sobre produtividade em paredes de concreto, que retratará o desempenho das obras de Salvador, fornecendo, subsídios para planejamentos, orçamentos, e avaliação de produtividade dentro da obra.
\end{abstract}

Palavras-chave: Produtividade, Indicadores de Desempenho, Benchmarking, Paredes de Concreto.

\begin{abstract}
The Brazilian construction sector had a massive developed in recent years, but the inefficiency of some processes and handcrafted construction methods of certain operations have not yet led to satisfactory productivity processes. Despite advances in the industry in terms of materials and construction techniques, the majority of the buildings sector still uses labor from low-skilled and low mechanization, using conventional processes and simple techniques. Therefore, there is a need to arise for measurement and comparison of productivity indicators related to different projects of
\end{abstract}


construction, especially the concrete walls process, due to the fact of this system has been recently adopted for housing, also presenting lack of data on productivity performance. This work aims to implement performance measurement for the structure on a concrete wall process, through the mobilization of the sector and the comparison of their performances. The research method of this work involves the following steps: (a) awareness and training of the participating companies, (b) selection of works and design of indicators, (c) data collection and monitoring visits, (d) data analysis and meetings to exchange experiences and results and, finally, (e) comparative analysis. This research contributes to the creation of a database with information on productivity in concrete walls, presenting the performance of the construction site in Salvador, providing grants for planning, budgeting, and evaluation of productivity within the work.

Keywords : Productivity, Performance Indicators, Benchmarking, Concrete Walls.

\section{INTRODUÇÃ̃O}

A competitividade do mercado da construção civil e a exigência cada vez maior dos clientes pela qualidade estão fazendo com que empresas do ramo da construção civil busquem melhorias nos seus processos construtivos e redução nos custos do seu orçamento. Uma meta importante que deve ser considerada para as empresas alcançarem esse objetivo é o aumento da produtividade nas diversas etapas dos processos construtivos.

As empresas da construção civil partem da premissa de que os problemas durante a execução de uma obra originam-se no canteiro de obras e devem ser resolvidos no âmbito operacional. Entretanto, a falta de uma visão estratégica para a obra de construção civil interfere na produtividade e causa perdas relacionadas às ações no canteiro de obras, e também, às ações da empresa como um todo (SACOMANO et al, 2004).

A escassez de mão de obra qualificada vem impactando na produtividade dos serviços, principalmente aqueles processos menos tradicionais, tais como execução de fôrmas metálicas, argamassa projetada e paredes de concreto (GUIMARÃES, 2012). Apesar do crescente aumento da inserção do sistema paredes de concreto em habitações no país, ainda são escassos os dados de medição de produtividade para o processo executivo deste sistema.

Frente a esta realidade, observa-se que para melhorar é preciso controlar a produtividade, e para isto a sua mensuração é imprescindível, possibilitando a comparação de indicadores de processos construtivos voltados à produção, como por exemplo, as paredes de concreto. Esses indicadores fornecem informações essenciais tanto para o planejamento e controle dos processos gerenciais, quanto para $\mathrm{o}$ monitoramento e o controle dos objetivos e metas estratégicas (COSTA, 2002).

Este trabalho tem como objetivo principal a mensuração e análise da produtividade por meio da implantação de um sistema de indicadores de produtividade do trabalho na execução de paredes de concreto armado (fôrma, armação e concretagem). Este trabalho faz parte do projeto Sistema de Indicadores de Produtividade e Perdas em Processos a Base de Cimento financiado pela Comunidade da Construção e desenvolvido pelo Grupo de Gestão e Tecnologia das Construções (GETEC) da Escola Politécnica da Universidade Federal da Bahia. O projeto, que se encontra no seu segundo ciclo, 
envolve a mobilização do setor e a criação de um Clube de Benchmarking sobre produtividade (COSTA et al., 2013).

\section{PAREDES DE CONCRETO}

O sistema de paredes de concreto surgiu no Brasil nos anos 80 , sendo inspirado em experiências consagradas e bem sucedidas de construções industrializadas em concreto celular (sistema Gethal) e concreto convencional (sistema Outinord), que eram mundialmente conhecidas desde a década de 70 (MASSUDA, 2009).

Embora seja um sistema concebido desde a década de 70 , as paredes de concreto tiveram seus altos e baixos, não sendo tão frequentes no cenário nacional (ARÊAS, 2013). Dentro do cenário atual, o sistema de parede de concreto vem conquistando o mercado brasileiro, oferecendo as vantagens de uma metodologia construtiva voltada à produção de edifícios em larga escala. Hoje, o sistema é recomendável para empreendimentos que têm alta repetitividade, exigem prazos de entregas exíguos, economia e otimização da mão de obra (ABCP, 2007).

O processo executivo de parede de concreto é resumido, basicamente, na montagem de formas metálicas, plásticas ou mistas e o preenchimento de concreto. Entre as fôrmas de paredes são posicionadas as ferragens e os itens de instalações prediais elétricas, hidráulicas e de gás. Porém, as instalações prediais hidrossanitárias são, geralmente, executadas por fora das paredes (por meio de shafts), assim se houver algum tipo de vazamento na tubulação não há necessidade de rompimento do concreto para execução dos devidos reparos. A industrialização deste processo construtivo está, justamente, no modo prático de se construir as paredes (MASSUDA, 2009).

Segundo Arêas (2013), a viabilidade do processo de parede de concreto está bastante relacionada ao tempo da construção. Por meio deste processo construtivo, existem construtoras no Brasil, que executam cerca de $100 \mathrm{~m}^{2}$ de estrutura predial para cada jogo de fôrma presente na obra. Logo, a partir da fundação/laje piso pronta, executam-se as paredes e lajes, já com todos os itens de instalações prediais posicionados, em apenas um dia. A Figura 1 mostra as atividades do processo construtivo de paredes de concreto.

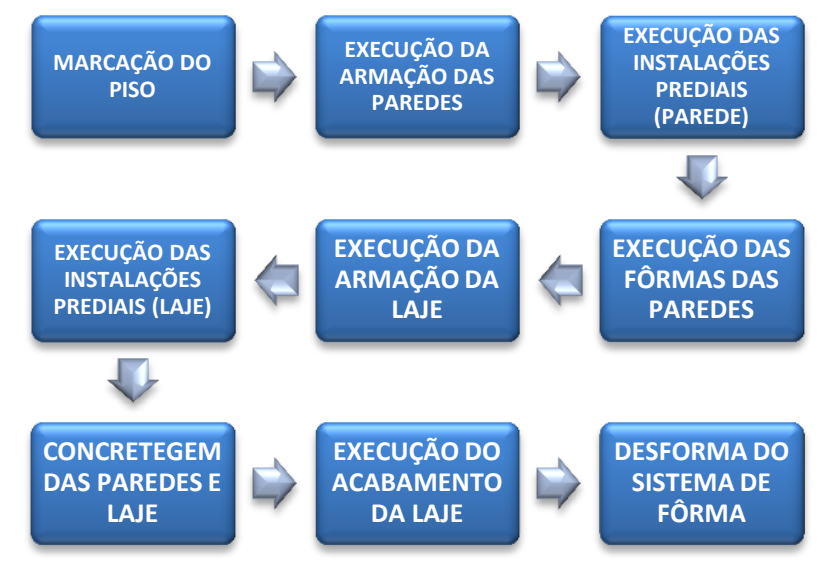

Figura 1 - Ciclo de execução paredes de concreto (Fonte: Arêas, 2013).

\section{MÉTODO DE PESQUISA}

Este trabalho foi desenvolvido por meio das seguintes etapas: revisão bibliográfica, sensibilização e capacitação das empresas participantes, seleção das obras e concepção 
dos indicadores, coleta dos dados, visitas de acompanhamento, análise dos dados, reuniões para troca de resultados e experiências e, por fim, análise comparativa entre as obras e seus processos utilizados.

A sensibilização e capacitação das empresas participantes ocorreram por meio de uma reunião realizada no dia 19 de setembro de 2013 em Salvador - BA. A pesquisa foi realizada com a participação de 10 empresas construtoras de Salvador, sendo que duas destas empresas possuíam obras com o sistema de estrutura em parede de concreto, denominadas de Obra A e a Obra B.

Após a seleção das obras, foi discutida a concepção dos indicadores de produtividade específicos para paredes de concreto, quais sejam: fôrma, armação e concretagem. A medição foi realizada por meio de um indicador, denominado RAZÃO UNITÁRIA DE PRODUÇÃO (RUP), que correlaciona o esforço dos trabalhadores (medido em homens-hora demandados) pela quantidade de serviço realizado (ARAÚJO, 2000).

Onde $\boldsymbol{H}$ representa os funcionários ligados somente ao serviço que se está calculando a produtividade, $\boldsymbol{h}$ representa a hora efetivamente trabalhada e $\boldsymbol{Q s}$ representa a quantidade de serviço para qual se está calculando a RUP, conforme Figura 2.

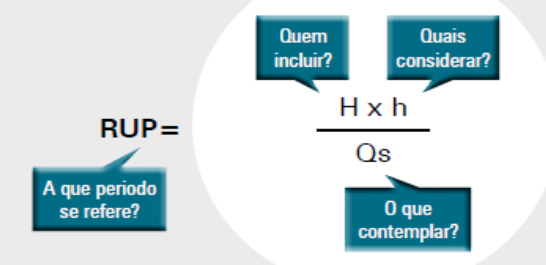

Figura 2 - Aspectos a padronizar quanto à mensuração da RUP (Adaptado de SOUZA, 2006).

Existem várias classificações e denominações para os tipos de RUP, que vão depender do seu uso e aplicação. Neste trabalho, foram analisadas a RUP por ciclo e a RUP cumulativa. A RUP por ciclo corresponde a quantidade de homem-hora da equipe direta trabalhada em relação à quantidade de serviço do ciclo de coleta, que no presente trabalho é o pavimento tipo. A RUP cumulativa representa o desempenho cumulativo nesses ciclos, levando em contas o somatório das quantidades de homem-hora da equipe direta e o somatório da quantidade de serviço realizado durante o período de estudo. Os indicadores selecionados estão apresentados no Quadro 1.

\section{Quadro 1 - Indicadores de produtividade para paredes de concreto}

\begin{tabular}{|c|c|}
\hline Processo & $\begin{array}{c}\text { Indicador de } \\
\text { produtividade }\end{array}$ \\
\hline $\begin{array}{c}\text { Estrutura em parede } \\
\text { de concreto } \\
\text { (parede e laje) }\end{array}$ & Fôrma $\left(\mathrm{Hh} / \mathrm{m}^{2}\right)$ \\
\cline { 2 - 2 } & Armação $(\mathrm{Hh} / \mathrm{Kg})$ \\
\cline { 2 - 2 } & Concretagem $\left(\mathrm{Hh} / \mathrm{m}^{3}\right)$ \\
\hline
\end{tabular}

Após a seleção dos indicadores foram desenvolvidas e apresentadas as planilhas de coleta dos dados para os responsáveis pelas obras para início das atividades. Na Obra A foram coletados e analisados dados de 24 ciclos (de 24 de setembro de 2013 a 04 de março de 2014) e na Obra B 30 ciclos (de 20 de novembro de 2013 a 18 de fevereiro de 
2014), ambas no processo de estrutura das paredes de concreto, incluindo fôrma, armação e concretagem.

Por fim, foram realizadas três reuniões de troca de resultados dos indicadores, nos dias 29 de outubro de 2013, 19 de dezembro de 2013 e 21 de fevereiro de 2014, que tiveram como objetivos discutir o porquê de algumas obras conseguirem alcançar um indicador maior ou menor em relação à outra obra, se a presença de tecnologia de alguma forma interferia na produtividade, além de discutir os diferentes métodos construtivos adotados, as suas vantagens e desvantagens do ponto de vista da eficiência e o potencial de melhoria.

\section{APRESENTAÇÃO E DISCUSSÃO DOS RESULTADOS}

Os itens a seguir descrevem o processo de paredes de concreto utilizado em cada uma das obras estudadas, destacando os principais resultados e a análise comparativa.

\subsection{Obra A}

A Obra A é localizada no bairro de São Rafael em Salvador- BA, correspondendo a um empreendimento formado por duas torres residenciais de 14 e 15 pavimentos, com 8 apartamentos por pavimento, totalizando 232 unidades habitacionais de padrão econômico. Os dados foram coletados nas torres 01 e 02 .

O pavimento era dividido em dois lados (A e B) e o sistema de produção seguia esta mesma divisão. O lado A correspondia a $44 \%$ da área total do pavimento e o lado $\mathrm{B}$, que contemplava a escada e poço do elevador, tinha $56 \%$ da área do pavimento. Como a arquitetura era simétrica, a obra utilizava fôrma para metade do pavimento, envolvendo as fôrmas de 4 apartamentos mais as fôrmas da escada e poço do elevador. $\mathrm{O}$ ciclo se iniciava com a marcação no piso e a montagem das armaduras e instalações das paredes do lado B, na sequência eram montadas as fôrmas das paredes e lajes e a equipe de armação voltava para este lado para seguir com a armação das lajes, que era acompanhada pelas instalações. Em seguida, as paredes e lajes deste lado do pavimento eram concretadas, levando em média 4 dias para a conclusão do lado B.

Após a montagem das armaduras do lado B, as equipes de armadores e instaladores já iniciavam os trabalhos no lado A. A equipe de fôrma realizava a desmontagem dos painéis do lado $\mathrm{B}$ (concretado no dia anterior) e, posteriormente, iniciava-se a montagem das fôrmas no lado $A$, utilizando a mesma sequência apresentada anteriormente, sendo o ciclo finalizado com a concretagem do lado A do pavimento. $\mathrm{O}$ lado A teve ciclo médio de produção de 3 dias.

Para a execução da armação das paredes e lajes foram utilizadas telas de aço soldadas. As bordas, vãos de portas e janelas receberam reforços de telas e barras de aço, totalizando em média $8.933 \mathrm{Kg}$ de aço por pavimento. O aço era cortado e dobrado na obra e o transporte das ferragens era realizado de forma manual do estoque até o térreo da torre e depois era elevado até o pavimento por meio de guincho foguete. Este serviço era realizado pela equipe própria da obra A, formada por 7 armadores e 6 serventes.

As fôrmas nesta obra eram de alumínio, que chegavam ao canteiro de obras prontas para a montagem com área de $2.012,56 \mathrm{~m}^{2}$ por pavimento. A equipe responsável pelo serviço de fôrma era composta por mão de obra própria. No início da obra a empresa realizou seus treinamentos específicos e a cada ciclo completo das fôrmas existiam em média 10 montadores e 18 serventes trabalhando. 
O concreto era usinado e fornecido por meio de caminhão betoneira para a Obra A. Nos ciclos coletados, o concreto foi transportado até o pavimento de concretagem por meio de bomba lança. A equipe responsável pela concretagem da Obra A era terceirizada, sendo composta em média por 6 pedreiros e 7 serventes.

Para ilustrar a coleta de dados nesta obra, as Figuras 3 e 4 apresentam as RUP de armação e fôrma, para oficiais e serventes. Como a coleta de dados começou desde o primeiro pavimento (ciclo 1), pôde-se observar o efeito aprendizagem nos serviços de armação e fôrma para ambos os profissionais.

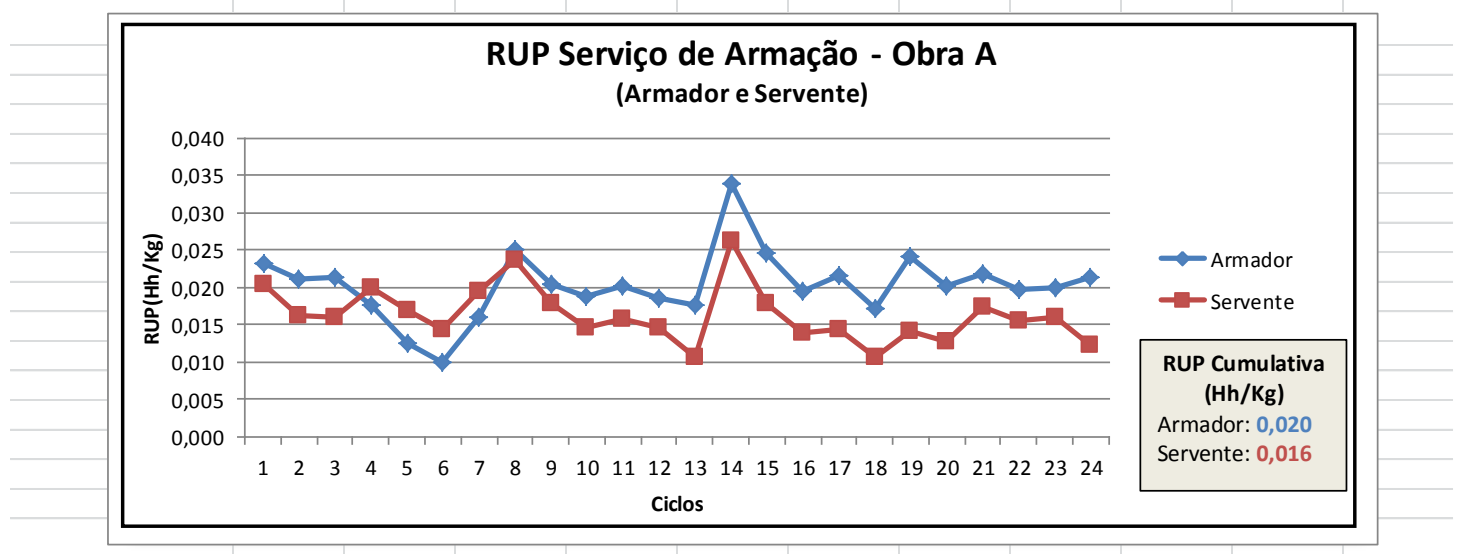

Figura 3 - Gráficos de tendência de produtividade dos serviços de armação para oficiais e serventes da obra A.

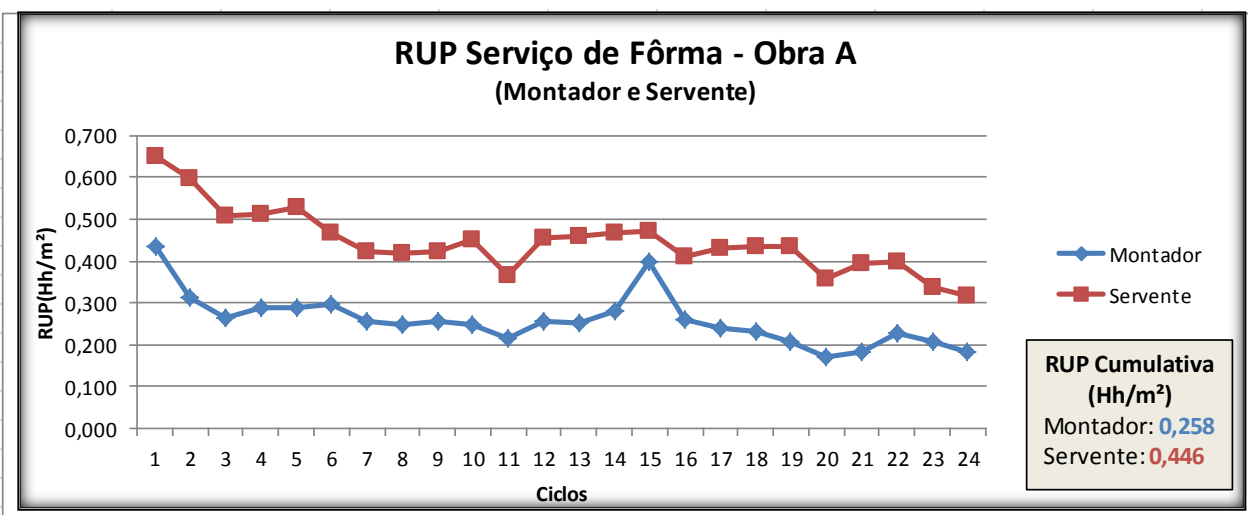

Figura 4 - Gráficos de tendência de produtividade dos serviços de fôrma para oficiais e serventes da obra A.

\subsection{Obra B}

Localizada na Estrada das Pedreiras, próximo ao Centro de Abastecimento de Salvador (CEASA), a obra B constituía um empreendimento formado por 90 blocos residenciais de 5 pavimentos cada, possuindo 4 apartamentos por pavimento, totalizando 1800 unidades habitacionais. A obra fazia parte do Programa Federal "Minha Casa Minha Vida" (na faixa 0 - 3 salários mínimos). Os dados foram coletados em 6 blocos.

A obra B possuía 5 jogos de fôrma, sendo que cada jogo de fôrma possibilitava a concretagem diária de 2 apartamentos em blocos diferentes, dando um total diário de 10 apartamentos. Cada bloco era erguido com um jogo completo de fôrma, que possuía uma equipe fixa de profissionais para os serviços de armação e fôrmas. A fôrma dividia 
o pavimento de 191,22 $\mathrm{m}^{2}$ em dois lados (A e B), sendo o lado A contemplando 2 apartamentos, hall e escada e o lado B que contemplava 2 apartamentos, realizando assim com um jogo de fôrma, um pavimento com quatro apartamentos a cada dois dias.

O ciclo se iniciava com a marcação do piso e com a armação das paredes e instalações do lado A, em seguida eram montadas as fôrmas paredes e lajes do lado A em paralelo com a execução das armaduras do lado B. Estas duas tarefas eram finalizadas no turno da manhã. No final da manhã, eram executadas a armação e instalações da laje do lado A. No início da tarde iniciava a concretagem de todo o lado A do pavimento. No dia seguinte, as fôrmas eram retiradas do lado A e montadas no lado B, seguindo a mesma sequência adotada anteriormente.

Na Obra B foram utilizadas telas de aço soldadas para a execução da armação das paredes e lajes e reforços com barras de aço. Cada pavimento possuía em média 1.565 $\mathrm{Kg}$ de aço, que era cortado e dobrado na obra. O transporte das ferragens até o pavimento era feito com o auxílio de um manipulador telescópico. O serviço de armação era realizado por equipe própria, formada por 4 armadores e 2 serventes.

As fôrmas eram de alumínio, que chegavam ao canteiro de obras prontas para a montagem com área de $871,38 \mathrm{~m}^{2}$ por pavimento. A equipe responsável por este serviço era composta por mão de obra própria e com média 14 montadores e 10 serventes.

$\mathrm{Na}$ obra $\mathrm{B}$, o concreto também era usinado e fornecido por meio de caminhão betoneira. O concreto era transportado até o pavimento de concretagem por meio de bomba lança. Seguindo a mesma sequência das fôrmas e das armaduras, a concretagem do pavimento foi dividida entre os dois lados $\mathrm{A}$ e $\mathrm{B}$ e a cada dia um lado do pavimento era concretado. A equipe de concretagem era terceirizada, composta por 4 pedreiros e 3 serventes.

O sistema de produção adotado pela obra B é distinto da obra A, pois ocorre definição de tarefas diárias em que o operário (oficial e servente) é dispensado ao fim do serviço por não ter como alocá-lo em outra atividade. Independentemente da equipe ser dispensada mais cedo, a mesma é remunerada por todo o dia de trabalho e, sendo adicionadas bonificações de incentivos aos seus salários. Para o cálculo da RUP, foram consideradas as horas pagas ao funcionário, excluindo o valor da hora prêmio.

As Figuras 5 e 6 apresentam RUP de armação e forma para oficiais e serventes, respectivamente. Há uma discrepância nos valores em alguns ciclos, devido ao fato dos operários não terem conseguido terminar o pacote de serviço no tempo estipulado, portanto, foi necessário pagar o equivalente a dois dias de trabalho.

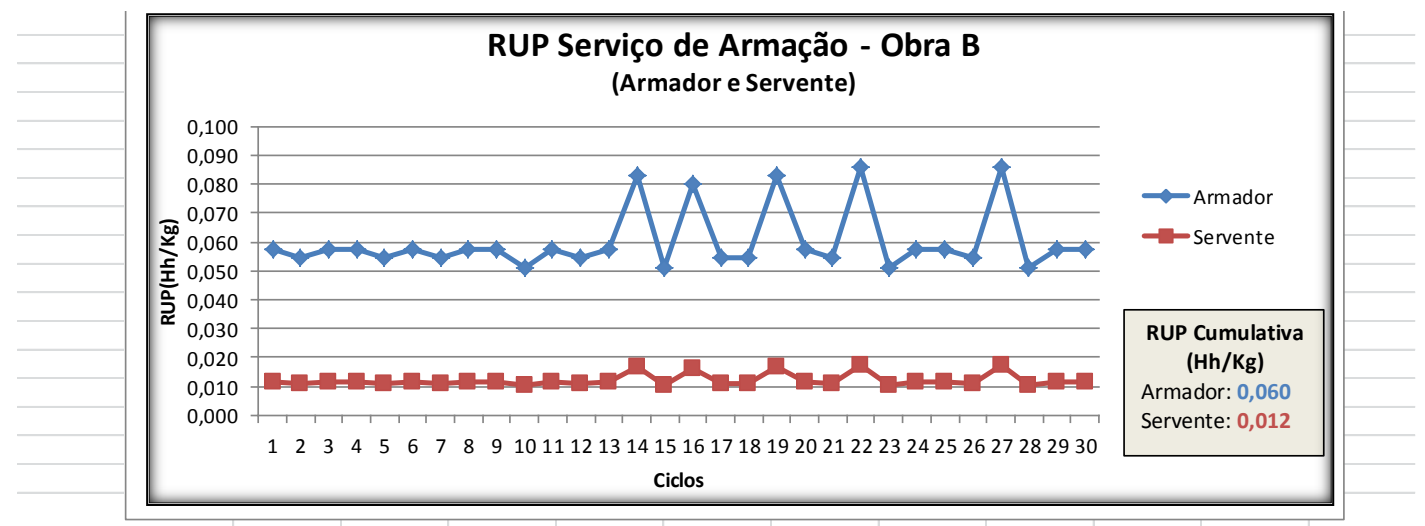

Figura 5 - Gráficos de tendência de produtividade dos serviços de armação para oficiais e serventes da obra $B$ 


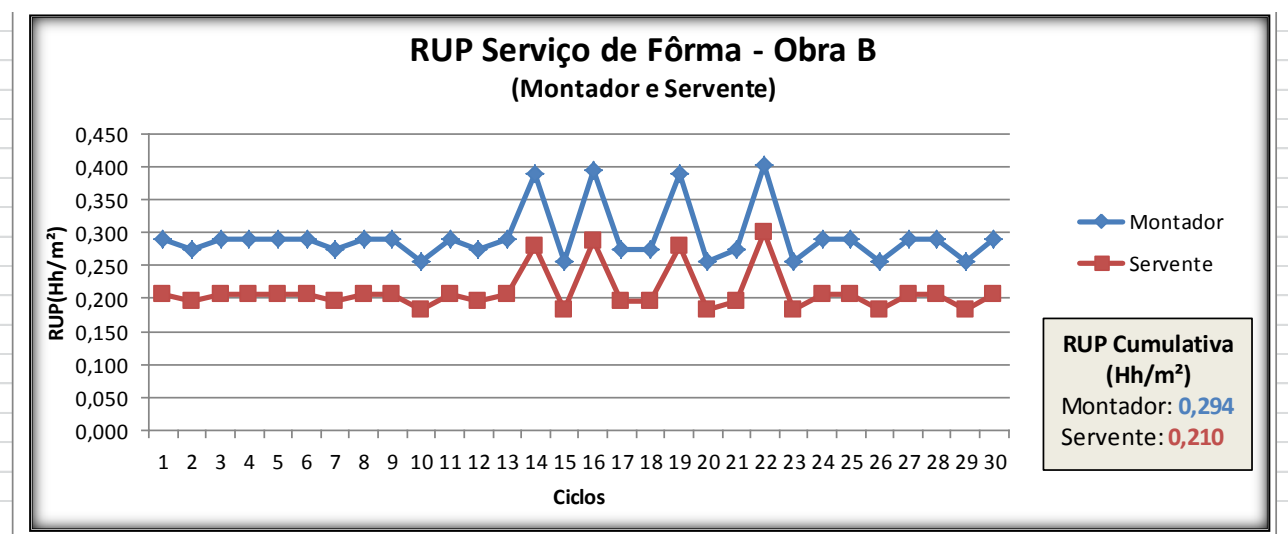

Figura 6 - Gráficos de tendência de produtividade dos serviços de fôrma para oficiais e serventes da obra B

\subsection{Análise Comparativa entre a Obra A e Obra B}

A partir da análise de cada estudo, é interessante avaliar comparativamente as duas obras, analisando os seus desempenhos na execução do serviço de execução das paredes de concreto.

A Tabela 1 apresenta os valores das RUPs de pavimento como valores mínimos (benchmarking) e máximos do processo de paredes de concreto para as duas obras estudadas, para os serviços de armação, fôrma e concretagem, além da RUP cumulativa.

Tabela 1 - Indicadores de produtividade para paredes de concreto

\begin{tabular}{|c|c|c|c|c|c|}
\hline \multirow[b]{2}{*}{ Indicador } & \multirow[b]{2}{*}{ Função } & \multirow[b]{2}{*}{$\begin{array}{c}\text { RUPpav } \\
\text { Benchmarking }\end{array}$} & \multirow{2}{*}{$\begin{array}{l}\text { RUP pav } \\
\text { Máximo }\end{array}$} & \multicolumn{2}{|c|}{ RUP Cumulativa } \\
\hline & & & & $\begin{array}{c}\text { Obra } \\
\text { A }\end{array}$ & Obra B \\
\hline \multirow{2}{*}{$\begin{array}{l}\text { RUP Armação } \\
(\mathrm{Hh} / \mathrm{Kg})\end{array}$} & Armador & 0,010 & 0,086 & $\mathbf{0 , 0 2 0}$ & $\mathbf{0 , 0 6 0}$ \\
\hline & Servente & 0,010 & 0,026 & 0,016 & 0,012 \\
\hline \multirow{2}{*}{$\begin{array}{c}\text { RUP Fôrma } \\
\left(\mathrm{Hh} / \mathrm{m}^{2}\right)\end{array}$} & Montador & 0,171 & 0,434 & $\mathbf{0 , 2 5 8}$ & 0,294 \\
\hline & Servente & 0.184 & 0,650 & 0,446 & 0,210 \\
\hline \multirow{2}{*}{$\begin{array}{l}\text { RUP Concretagem } \\
\left(\mathrm{Hh} / \mathrm{m}^{3}\right)\end{array}$} & Pedreiro & 0,064 & 0,959 & 0,623 & $\mathbf{0 , 0 9 3}$ \\
\hline & Servente & 0,068 & 0,918 & 0,638 & $\mathbf{0 , 1 3 4}$ \\
\hline
\end{tabular}

Para o serviço de armação, os dados da Tabela 1 mostram uma RUP cumulativa três vezes maior para os armadores da Obra $\mathrm{B}(0,060 \mathrm{Hh} / \mathrm{Kg})$ em relação a armadores da Obra A $(0,020 \mathrm{Hh} / \mathrm{Kg})$. Porém, para os serventes isto não acontece, a RUP de 0,012 $\mathrm{Hh} / \mathrm{Kg}$ dos serventes na Obra $\mathrm{B}$ um pouco inferior à alcançada pelos serventes da obra A que foi de $0,016 \mathrm{Hh} / \mathrm{Kg}$. Observa-se que esta divergência de resultados se dá, principalmente, pelo dimensionamento da equipe. A Obra A apresentou uma relação oficial: servente de 1:1, mantendo-se mais eficiente quando comparada a obra B que apresentou uma relação de $2: 1$, no entanto, se a Obra B, redimensionasse a equipe, esta não seria capaz de realizar a atividade no tempo determinado pelo plano de ataque.

Em relação à fôrma, a Obra $\mathrm{A}$ obteve para os seus montadores uma RUP de 0,258 $\mathrm{Hh} / \mathrm{m}^{2}$ e a obra B conseguiu uma RUP de $0,294 \mathrm{Hh} / \mathrm{m}^{2}$, valores muito próximos. Como é possível observar, apesar do plano de ataque das obras A e B serem diferentes, as obras alcançaram uma produtividade parecida para os serviços. Isso é justificado pelo 
alto grau de industrialização do processo construtivo, trazendo padronização dos serviços.

Para o serviço de concretagem as variações das RUPs cumulativas entre as obras alcançaram grandes diferenças. A Obra B obteve uma RUP para pedreiro de 0,093 $\mathrm{Hh} / \mathrm{m}^{3}$, enquanto que a Obra A alcançou $0,623 \mathrm{Hh} / \mathrm{m}^{3}$ de RUP para o mesmo profissional do serviço. Para os serventes isso não foi diferente, a RUP da Obra A foi de $0,638 \mathrm{Hh} / \mathrm{m}^{3}$ contra $0,134 \mathrm{Hh} / \mathrm{m}^{3}$ de RUP da Obra B. O processo de concretagem já deixa de ser repetitivo e passa a ter outros fatores que influenciam na produtividade. Os principais fatores que provocaram a baixa produtividade no serviço de concretagem da Obra A foram a ociosidade de alguns membros da equipe e a complexidade dos serviços. O acabamento era realizado com acabadora de superfície (helicóptero) em toda extensão da laje, o que demandava bastante tempo. A concretagem na obra A era interrompida constantemente pelo atraso no fornecimento do concreto, gerando assim grande ociosidade por parte dos funcionários. Além disso, uma equipe grande tendeu a diminuir ainda mais a produtividade, uma vez que o controle desta equipe e a divisão do trabalho são mais complicados.

\section{CONCLUSÃO}

Mesmo já tendo implantado o Sistema de Indicadores de Perdas e Produtividade há dois anos em obras de Salvador, este foi o primeiro estudo de medição de desempenho desenvolvido pela Comunidade da Construção da Bahia envolvendo paredes de concreto. As empresas tiveram interesse em participar da concepção destes novos indicadores e da criação do banco de dados de produtividade, contribuindo assim para a caracterização deste sistema ainda pouco usado na região. Os dados e informações obtidas ajudarão não só as empresas participantes, mas contribuirão com outras empresas que precisam avaliar e conhecer o potencial desempenho produtivo do sistema de paredes de concreto em Salvador e região metropolitana.

O procedimento de coleta foi feito de forma padronizada, respeitando as diferenças de cada empresa, mas priorizando que elas coletassem da mesma forma, para serem possíveis comparações e o estabelecimento de critérios bem definidos de como e o que contemplar na coleta dos dados, gerando transparência quanto às informações obtidas. Diante disso, foi possível obter dados confiáveis que representam o atual desempenho das empresas estudadas, contribuindo como ferramenta para posteriores tomadas de decisões e utilização nas composições de orçamentos futuros.

Com os dados coletados e avaliando os resultados das duas obras, foi possível concluir que o sistema de produção e o plano de ataque adotado pelas empresas podem interferir diretamente na sua produtividade. O sistema de paredes de concreto apresenta características que apontam para um processo com alto nível de industrialização, com isso, é imprescindível a adoção de um ciclo de produção eficiente que potencialize a produção em escala, uma vez que as paredes de concreto se apresentam como boa alternativa do ponto de vista da imperativa necessidade de aumento de produtividade através da industrialização dos processos e redução da mão de obra.

Por outro lado, os indicadores de produtividade precisam ser bem avaliados e utilizados de forma correta, sendo inseridos para a avaliação e acompanhamento de cada setor específico da empresa. A utilização de preços fixos para a hora-homem de trabalho e quantificações pré-estabelecidas por algum sistema auxiliar de orçamento faz com que na maioria dos casos, haja inserção de horas extras e bonificações para os funcionários. Isso acontece devido ao fato da empresa não conhecer a real produtividade do 
funcionário e o valor real do seu custo para o orçamento. A inserção de custos adicionais para evitar "furos" na sua contabilidade acaba "camuflando" os valores efetivos de cada serviço. Desta forma, observa-se importância de uma quantificação detalhada dos serviços, das horas despendidas para a realização do mesmo e do custo para as obras. Observa-se então a relevância de se ter indicadores próprios de produtividade da mão de obra.

\section{REFERÊNCIAS}

ASSOCIAÇÃO BRASILEIRA DE CIMENTO PORTLLAND - ABCP. Parede de Concreto Coletânea de ativos 2007/2008.

ASSOCIAÇÃO BRASILEIRA DE NORMAS TÉCNICAS. NBR-16005. Parede de concreto moldada no local para a construção de edificações - Requisitos e procedimentos. ABNT: Rio de Janeiro, 2012.

ARAÚJO, L. O. C. de. Método para a previsão e controle da produtividade da mão de obra na execução de fôrmas, armação, concretagem e alvenaria. Dissertação (Mestrado em Engenharia Civil) - Universidade de São Paulo, São Paulo, 2000.

AREAAS, D. M. Descrição do Processo Construtivo de Parede de Concreto para Obra de Baixo Padrão. Projeto de Graduação - Escola Politécnica. Universidade Federal do Rio de Janeiro. Rio de Janeiro, 2013. 70p.

COMUNIDADE DA CONSTRUÇÃO. Boas Práticas, 2012. Disponível em:

$<$ http://www.comunidadedaconstrucao.com.br/boas-praticas/14/uso-doagentedesmoldanteadequado.html>. Acesso em: 20 nov. 2013.

COSTA, D. B. Diretrizes para a realização de processo de benchmarking colaborativo visando à implementação de melhorias em empresas de construção civil. Tese (doutorado) Universidade Federal do Rio Grande do Sul. Escola de Engenharia. Programa de Pós-Graduação em Engenharia Civil. Porto Alegre, 2008. 310p.

COSTA et al. Caderno de Resultados Sistema de Indicadores de Produtividade e Perdas. Comunidade da Construção, Salvador, 2013.

DUARTE, C. M. de M. Desenvolvimento de sistema de indicadores para Benchmarking em empresas de construção civil. Dissertação (Mestrado em Engenharia Civil) - Programa de Pós-Graduação em Engenharia Civil, Escola Politécnica de Pernambuco, Universidade de Pernambuco, Recife, 2011.

GUIMARÃES, C. D. Análise de Indicadores de Produtividade e Perdas na Fase de Estrutura de Obras de Edificações. Monografia (Trabalho de Conclusão de Curso) - Escola Politécnica. Universidade Federal da Bahia. Salvador, 2012. 130p.

MASSUDA, C. Como construir Parede de concreto. 2009. Disponível em: $<$ http://www. engemix.com.br/cserie/attach/manual/revista_techne.pdf $>$. Acesso em: 21 nov. 2012.

PEREIRA, E. A. Diretrizes de Gestão para Obras Habitacionais de Interesse Social. Dissertação de Mestrado, Faculdade de Engenharia Civil, Universidade Federal de Uberlândia, 2008. $174 \mathrm{p}$.

SACOMANO et al. Administração de Produção na Construção Civil: o gerenciamento de obras baseado em critérios competitivos. São Paulo: Arte \& Ciência, 2004. 204p.

SOUZA, U.E.L. Como Aumentar a Eficiência da mão de obra - Manual de Gestão da Produtividade na Construção Civil. São Paulo; Editora Pini; 2006. 100p. 